\title{
Influence of Basketball Training on Selected Saliva Components in Male Youth Players
}

\author{
Iwona Grzesiak-Gasek $^{1^{*}}$, Marek Gasek ${ }^{2}$, Urszula Kaczmarek ${ }^{1}$
}

${ }^{1}$ Department of Conservative Dentistry and Pedodontics, Wroclaw Medical University, Rektorat, wybrzeże Ludwika Pasteura 1, 50-367 Wrocław, Poland

${ }^{2}$ Axis Software Marek Gasek Sztabowa tsr. 76a/11 53-310 Wocław, Poland

*Corresponding author: Iwona Grzesiak-Gasek

The aim of the study was to assess the impact of a single basketball players' training on the levels of selected salivary components. Thirty male basketball players, aged 12-15 (study group), and ten sedentary subjects (control group) were enrolled in the study. A routine training took place in an indoor basketball court. Unstimulated mixed saliva samples were collected in the afternoon in both groups, in basketball players twice before and after training. In salivary supernatants total protein, $\alpha$-amylase, peroxidase, free acid sialic, cortisol, total antioxidant status (TAS), calcium and magnesium were measured, as well as salivary flow rate. Moreover, the basketball players evaluated the workout intensity using the perceived exertion scale (RPE Foster's scale). In basketball players after the training a significant decrease in the salivary flow rate $(\mathrm{p}=0.047)$, and an increase in $\mathrm{pH}(\mathrm{p}=0.011)$ and TAS $(\mathrm{p}=0.010)$ were observed as well as a higher output higher only of alpha-amylase $(\mathrm{p}=0.024)$, TAS $(\mathrm{p}=0.023)$ and magnesium $(\mathrm{p}=0.008)$. Compared the athletes before workout with the controls no significant difference in the salivary components was found, except level of peroxidase and output of peroxidase and total protein in the control group $(p=0.007, p=0.003, p=0.049)$. Mean value of Foster's RPE scale was $4.70 \pm 1.64$, and most players perceived the training as "somehow hard" and "hard". The Foster's RPE score was correlated with difference in the pre- and post-training content of FSA (rho=0.428, $\mathrm{p}=0.018$ ). Within the limitation of the study we observed an increase of the levels of $\mathrm{pH}$, TAS, output of alphaamylase, TAS magnesium.

Keywords: Physical exercise; basketball; RPE; saliva.

Copyright @ 2019: This is an open-access article distributed under the terms of the Creative Commons Attribution license which permits unrestricted use, distribution, and reproduction in any medium for non-commercial use (NonCommercial, or CC-BY-NC) provided the original author and source are credited.

\section{INTRODUCTION}

Physical exercise causes many changes in the biochemical parameters of the body, which modify components of the blood and saliva among other body. It has been reported that measuring salivary constituents reflecting their levels in the blood following exercise can be a noninvasive method to assess biomarkers of exercise intensity and recovery.

Activity of the sympathetic nervous system increases progressively with the intensity of exercise, altering some salivary components and due to narrowing of blood vessels within salivary glands decreases the amount of secreted saliva. Meanwhile, an activation of the parasympathetic nervous system causes an increase of secretion [1].
Physical exercise also causes an increase in vasopressin (an antidiuretic hormone) which can decrease production of saliva.

Physical exercise can cause changes in the concentration of organic (proteins, enzymes, hormones) and inorganic $(\mathrm{Na}, \mathrm{K}, \mathrm{Ca}, \mathrm{Cl})$ components of saliva. Physical exercise increases concentrations of cortisol in the blood, known as stress hormone (physical and psychological), which has significant influence on the body metabolism. Unbound fractions of cortisol infuse into bodily fluids through passive diffusion, including saliva, which cause the level of cortisol within plasma to correlate with the levels of cortisol within saliva. Thus, salivary cortisol can be an indicator of bodily responses to physical and psychological stress [2]. However, exercise of low intensity is usually associated with slower increase or even stopping of the production of cortisol [3]. It has been shown that concentration of circadian rhythm in blood, highest in the morning and 
lowering throughout the day to be lowest in the evening, as well as levels of cortisol, is higher during physical exercise in mornings rather than evenings [2].

Proteins in saliva are released at the activation of the sympathetic nervous system. The enzyme alfaamylase is synthetized mainly in the parotid glands and the rest in the submandibular glands which accounts for $40-50 \%$ of the total protein in saliva which is a clear marker reflecting the activated sympathetic nervous system and thus can be used as an alternative in identifying catecholamines (adrenalin and noradrenalin) and cortisol. Alpha-amylase is also used as a marker of physical and psychological stress, as it has been found that it increases with activity [4].

During physical exercise there is an increase in the metabolic systems activity and the use of oxygen (in accordance to the increased metabolism, especially in the skeletal muscles), which cause an increase in Reactive Oxygen Species (ROS). In the correct environment, ROS are eliminated by interior and exterior cells in the protective system. Enzyme and nonenzyme antioxidants delay and stop oxidation of substrates [5]. Studies have shown increases in levels of antioxidants following physical exercise [6]. Additionally, increase in levels of electrolytes, such as magnesium, sodium, and manganese, following exercise has been found in saliva [7].

The objective of the present study was to investigate whether a single session of a routine basketball workout affects levels of selected salivary components in boys aged 12-15 years.

\section{MATERIALS AND METHODS}

The study included 40 male adolescents aged from 12 to 15 (mean $13 \pm 0.5$ years), of which 30 were basketball players (study group) and 10 sedentary individuals (control group). Participation in the study was voluntary. The basketball players attended a sports school and the control a standard secondary school. Inclusion criteria were as follows: age between 12 and 16, no acute or chronic systemic disease, no medications usage before or during this study, training basketball regularly 5 times a week ( 7.5 hours weekly) for at least six months or no engagement in any sports activities (control group). The exclusion criteria included the subjects younger than 12 and over 16 , periodical engagement in sports and the presence of acute or chronic diseases. A routine 90-minute training session contained a warm-up, physical, technical, tactical and game workouts. Sport trainings took place in an indoor basketball court in the afternoon and lasted one and a half an hour (from 4:00 to 5:30).

In the study group salivary samples were collected twice, before and after workout and in the control group once a day at the time of the pre-workout sampling in athletes. In total 70 samples of saliva were collected. Salivary samples were collected after thoroughly rinsing the mouth with distilled water. The subjects were sitting with the head bent down and the mouth open. The salivary samples was collected from the floor of the mouth, with the use of a plastic pipette, and put into a graded test tube stored on crushed ice. Based on the measurement of the volume of the collected salivary sample and the time needed for its collection, salivary flow rate was calculated as $\mathrm{ml} / \mathrm{min}$ (V). The samples were centrifuged for 10 minutes at a speed of $3500 \mathrm{rpm}$ before chemical assays. Total protein - P (by Lowry's et al., method), pH (by potentiometric method), $\alpha$-amylase (by Caraway's colorimetric method-Alpha Diagnostic Kit), salivary peroxidase - SPO (using Nbs-SCN method), free acid sialic - FSA (by periodate-resorcinol method), cortisol (Elisa Kit from R\&D Systems), total antioxidant status (TAS assay Randox), calcium (by method based on formation of chromogenic complex between calcium ions and o-cresolphthaelin using Alpha Diagnostics kit), magnesium (by colorimetric method based on the reaction of magnesium with Xylidyl Blue-I using Alpha Diagnostics kit) were assessed. The data obtained from the measurements were presented in units and as an output, i.e. concentration of a specific component obtained within 1 minute.

Moreover, the intensity of the workout was self-assessed by the basketball players using Foster's scale (modified Borg CR-10) which is the categoryratio scale of perceived exertion rating (RPE) [8]. The category-ratio scale is characterized by scores and verbal links (i.e. from "rest" to "maximal") referring the athlete's perception of efforts to a numerical score between 0 (i.e. rest) and 10 (i.e. maximal). The Foster's RPE scale was administered around 30 minutes after the end of the training session to assess the internal load of the entire training session.

This study protocol has been approved by Bioethics Committee of the Medical University of Wrocław (No KB-327/2009).

Depending on the type of variables distribution, Student's t-test or Mann-Whitney test was used for the independent variables analysis. For the dependent variables, Student's t-test or non-parametric Wilcoxon's test was conducted. The Pearson's correlation between RPE scores and the difference in the salivary parameters before and after the training was calculated. The obtained data were analyzed at significance level set at $\mathrm{p}<0.05$ by STATISTICA 13.1 software package (StatSoft, Inc., Tulsa, OK, USA)

\section{RESULTS AND DISCUSSION}

Mean value of Foster's RPE scale was $4.70 \pm 1.64$ and ranged from 2 to 10 . Most players perceived the training as "somehow hard" (score 4, $\mathrm{n}=10$ ) and "hard" (score 5, n=10). Global training load for the session was $423 \pm 149.88$ A.U. 
Levels of the tested parameters before and after training session

A significant decrease in the salivary flow rate $(\mathrm{p}=0.047)$ and increase in $\mathrm{pH}(\mathrm{p}=0.011)$ and TAS $(\mathrm{p}=0.010)$ levels were observed after the training (Table-1).

Table-1: Levels of studied salivary parameters

\begin{tabular}{|c|c|c|c|c|c|}
\hline \multirow{3}{*}{ Salivary parameters } & \multirow{3}{*}{$\begin{array}{l}\text { Non- } \\
\text { basketball } \\
\text { (control } \\
\text { group) }\end{array}$} & \multirow{2}{*}{\multicolumn{2}{|c|}{ basketball study group }} & \multirow{3}{*}{\begin{tabular}{llr} 
Before & \multicolumn{2}{r}{ training } \\
basketball & vs & non- \\
basketball & &
\end{tabular}} & \multirow{3}{*}{$\begin{array}{l}\text { Basketball before } \\
\text { vs after training }\end{array}$} \\
\hline & & & & & \\
\hline & & before & after & & \\
\hline $\begin{array}{l}\text { Salivary flow rate }(\mathrm{V}) \\
\mathrm{ml} / \mathrm{min}\end{array}$ & $0.35 \pm 0.19$ & $0,49 \pm 0,23$ & $0.36 \pm 0.16$ & $\begin{array}{ll}\mathrm{u}=-1.702 & \mathrm{p}=0.089^{\mathrm{b}} \\
(\uparrow 40 \%) & \end{array}$ & $\begin{array}{l}\mathrm{z}=1.984 \\
\mathrm{p}=0,047^{\mathrm{c}}(\downarrow 26 \%)\end{array}$ \\
\hline $\mathrm{pH}$ & $7.53 \pm 0.49$ & $7.31 \pm 0.35$ & $7.51 \pm 0.26$ & $\mathrm{t}=1.57 \mathrm{p}=0.12^{\mathrm{a}}(\downarrow 3 \%)$ & $\begin{array}{l}\mathrm{t}=-2.712 \quad \mathrm{p}=0.011^{\mathrm{a}} \\
(\uparrow 3 \%)\end{array}$ \\
\hline Total protein $(\mathrm{P}) \mathrm{g} / \mathrm{l}$ & $1.40 \pm 0.71$ & $0.98 \pm 0.55$ & $1.20 \pm 0.83$ & $\begin{array}{ll}\mathrm{u}=1.624 & \mathrm{p}=0.104^{\mathrm{b}} \\
(\downarrow 30 \%) & \end{array}$ & $\begin{array}{l}\mathrm{z}=1.189 \quad \mathrm{p}=0.234^{\mathrm{c}} \\
(\uparrow 22 \%)\end{array}$ \\
\hline Amylase (Amy) j/ml & $170.98 \pm 107.72$ & $162.30 \pm 120.57$ & $193,83 \pm 115,00$ & $\mathrm{u}=0.312 \mathrm{p}=0.755^{\mathrm{b}}(\downarrow 5 \%)$ & $\begin{array}{ll}\mathrm{z}=1.244 & \mathrm{p}=0.213^{\mathrm{c}} \\
(\uparrow 19 \%) & \end{array}$ \\
\hline Cortisol (C) $\mu \mathrm{g} / \mathrm{ml}$ & $4.18 \pm 4.34$ & $3.38 \pm 1.81$ & $3.13 \pm 1.64$ & $\begin{array}{l}\mathrm{u}=-0.218 \\
(\downarrow 27 \%)\end{array}$ & $\begin{array}{l}z=1.717 \\
(\downarrow 16 \%)\end{array}$ \\
\hline $\begin{array}{l}\text { Total Antioxidant } \\
\text { Status (TAS) mmol/l }\end{array}$ & $0.59 \pm 0.41$ & $0.52 \pm 0.30$ & $0.69 \pm 0.32$ & $\begin{array}{l}\mathrm{u}=0.078 \\
(\downarrow 12 \%)\end{array}$ & $\begin{array}{l}\mathrm{z}=2.560 \\
(\uparrow 32 \%)\end{array}$ \\
\hline $\begin{array}{l}\text { Salivary peroxidase } \\
\text { (SPO) U/ml }\end{array}$ & $1.56 \pm 0.59$ & $0.85 \pm 0.92$ & $0.76 \pm 0.65$ & $\begin{array}{l}u=2.686 \\
(\downarrow 45 \%)\end{array}$ & $\begin{array}{l}\mathrm{Z}=0.133 \\
(\downarrow 11 \%)\end{array}$ \\
\hline $\begin{array}{l}\text { Free sialic acid (FSA) } \\
\mathrm{mg} \%\end{array}$ & $3.42 \pm 4.15$ & $3.68 \pm 2.10$ & $3.90 \pm 2.39$ & $\begin{array}{l}\mathrm{u}=-1.358 \\
(\uparrow 8 \%)\end{array}$ & $\begin{array}{l}\mathrm{z}=0.010 \\
(\uparrow 6 \%)\end{array}$ \\
\hline Calcium $(\mathrm{Ca}) \mathrm{mg} \%$ & $3.18 \pm 0.96$ & $4,39 \pm 2,12$ & $3,92 \pm 1,67$ & $\begin{array}{l}\mathrm{u}=-1.952 \\
(\uparrow 38 \%)\end{array}$ & $\begin{array}{l}\mathrm{z}=1.203 \quad \mathrm{p}=0.228^{\mathrm{c}} \\
(\downarrow 11 \%)\end{array}$ \\
\hline $\begin{array}{l}\text { Magnesium } \\
\mathrm{mg} \%\end{array}$ & $0.44 \pm 0.24$ & $0,49 \pm 0,39$ & $0,61 \pm 0,37$ & $\begin{array}{l}\mathrm{u}=-0.062 \\
(\uparrow 11 \%)\end{array}$ & $\begin{array}{l}\mathrm{z}=1.336 \\
(\uparrow 24 \%)\end{array}$ \\
\hline
\end{tabular}

a -t-student test; b- U-Mann-Whitney test; c- Wilcoxon test

The impact of exercise on relative changes in salivary components' concentrations, presented as $100 \%$ baseline value, is illustrated in Fig-1.

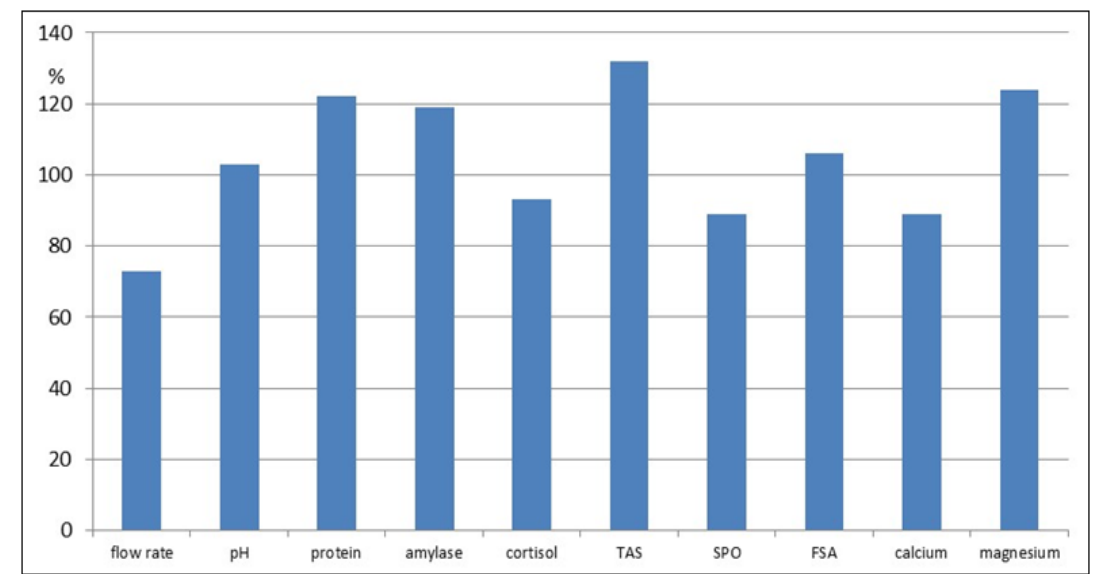

Fig-1: Effect of training basketball on relative changes in salivary parameters, levels before excercise were set at $100 \%$

The post-training increase ranging from 3 to $32 \%$ was noticed for $\mathrm{pH}$, FSA, alpha-amylase, total protein, magnesium and TAS, with a 5-27\% decrease being observed for GSA, cortisol, peroxidase, calcium and flow rate and no change for TSA. Regarding correlation between the differences in the pre- and posttraining salivary parameters' concentrations and
Foster's RPE scores, only FSA showed a significant positive correlation $(\mathrm{rho}=0.428, \mathrm{p}=0.018$ ). However, the output of the tested salivary components was slightly higher after the workout, being significantly higher only for alpha-amylase $(\mathrm{p}=0.024)$, TAS $(\mathrm{p}=0.023)$ and magnesium $(\mathrm{p}=0.008)($ Fig-2). 


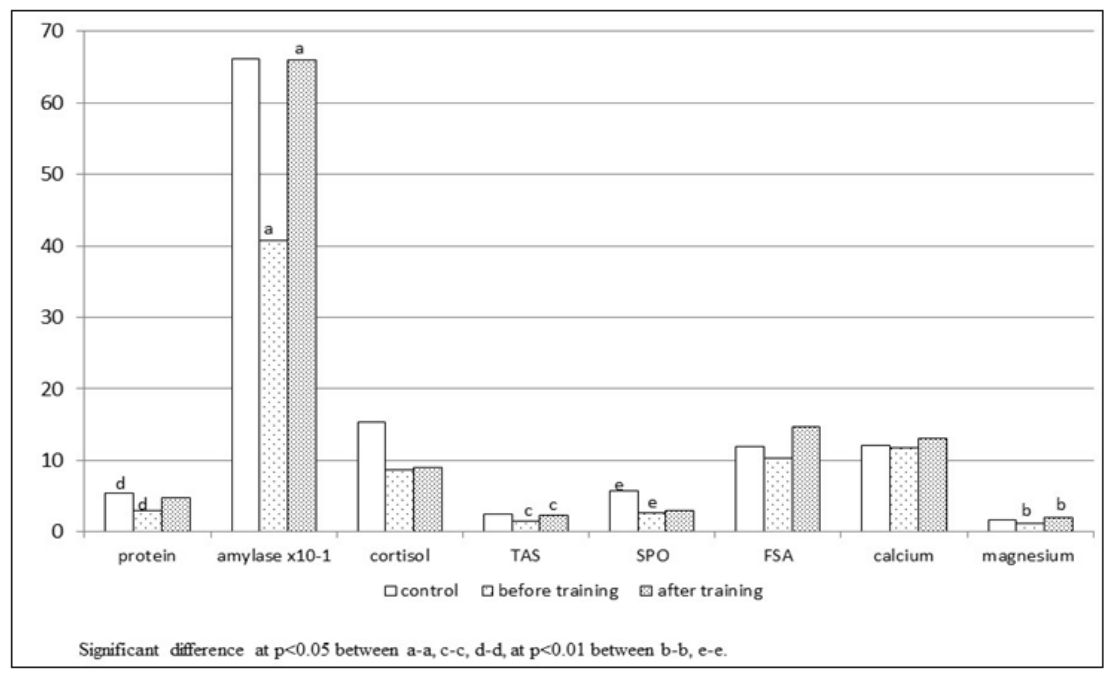

Fig-2: Output of salivary components (mg/ $\mu \mathrm{g} / \mathrm{U}$ per min.) in basketball players before and after training and control

Levels of the tested saliva parameters in basketball players before training session compared with the control group

There was no significant difference in the salivary components in the athletes before workout and in the controls, except a level of peroxidase and output of peroxidase and total protein $(\mathrm{p}=0.007, \mathrm{p}=0.003$, $\mathrm{p}=0.049$, respectively) which were higher in the control group (Table-1 and Fig-2).

Human saliva contains various kinds of compounds and its composition is selectively altered in response to exercise. This study was to assess the association between some salivary components' levels and a basketball players training session. The obtained data, similarly to other studies, showed some changes in the salivary components following a basketball training session. We found significant reduction of unstimulated salivary flow rate following the workout. However, it may suggest also that the hydration status of the athletes was affected by the training or that the athletes did not consume sufficient amount of fluid to avoid acute dehydration during the training. Levels of salivary total protein can be used to estimate the hydration status of athletes during training and competition. De Oliveira et al. [9] studied salivary total protein profile in male cyclists who underwent a progressive test. They found that an increased secretion of the salivary alphaamylase polypeptides indicated the enzyme as the main protein responsible for the increase in the whole salivary total protein concentration. Moreover, they postulated monitoring total protein concentration as an efficient measure for determining exercise intensity. However, contrary to $\mathrm{He}$ et al., [10] who found a significant change in total protein concentration caused by intense training and competition during a basketball season, we did not find any. Neither did our data reveal any significant differences in the total protein concentration and output following training session.
The observed increase of $\mathrm{pH}$ level following the workout could be associated with the drop of salivary flow rate. This observation was consistent with Wu et al., [11] results as they found positive correlation between unstimulated salivary flow rate and $\mathrm{pH}$.

Cortisol and salivary alpha-amylase have been used as indicators of physical and psychological stress. Their increases in saliva reflecting the activity of the sympathetic nervous system (in response to physical exertion and psychological stress associated with sports competition) were found $[9,12]$.

The subjects involved in this study were in the pubertal stage of development in which individuals undergo physical changes, caused by hormones, that lead to maturity. It has been assumed that cortisol concentration in the body does not change from childhood to adulthood [13]. However, measurements of salivary cortisol in infants, children, and adolescents revealed age dependency and correlation with pubertal stages and body weight [14].

We did not take into the account developmental parameters of the subjects as they were in a narrow range of ages.

Measurement of cortisol in saliva is widely used to assess physical stress response to exercise, training and environmenetal stress. However, the results showed that an elevated cortisol level in saliva after exercise depends on the intensity, duration of physical activity, exercise state (competition), psychological stimuli and time of day [15]. However, in some studies the cortisol concentration increased with sub-maximal exercise or training [16].

Findings of our study are in line with the results showing lack of significant changes or decline in salivary cortisol levels in response to physical activity as we observed a slight decrease in the cortisol level following the basketball training session [17, 18]. 
Bruzda-Zwiech et al., [18] observed a significant decrease of cortisol concentration in unstimulated saliva of young basketball players after a routine training. Moirera et al., [17] evaluating effect of match importance in elite young volleyball players found significantly lower session-RPE score after regular season match and no significant elevation of salivary cortisol as opposed to the final championship match. Therefore, lack of an increase in salivary cortisol could be associated with great physiological and psychological stress because it was a training session and not an official competition.

Salivary alpha-amylase has been proposed as a sensitive indicator for stress-related changes in the body reflecting the activity of the sympathetic nervous system and the hypothalamic-pituitary-adrenal as numerous studies have confirmed the validity and reliability of this parameter. However, different types of physical activity led to increase or no change in salivary amylase level [19]. Increase in salivary alpha-amylase has been found to be due to exercise psychological stress [9, 12]. Ligtenberg et al., [20] found significant increase in salivary amylase after a moderate intensity exercise but no difference between moderate and high exercise intensity. This enzyme was found to be significantly elevated in elite young basketball players from pre-to-post matches as well as after a single training. [18]. Our data also revealed some elevation of alpha-amylase concentration (approximately 19\%) and significant rise of output after a single basketball players training session.

Physical activity can cause an imbalance between radical oxygen species (ROS) production and antioxidants, named oxidative stress; however, it depends on the training type and intensity. Antioxidants can neutralize negative effects of free radicals and ROS, and decrease effects of oxidative stress [21]. Human saliva is rich in antioxidant compounds comprising enzymes (peroxidase, catalase, superoxide dismutase, glutathione peroxidase) and small molecules (uric acid, vitamin $\mathrm{E}, \mathrm{C}$ ). The antioxidant defense system has many components; a deficiency in any of these components can cause a reduction in the overall antioxidant status. Total antioxidant capacity (TAC) serving as a tool to assess the antioxidant status (TAS) is used to evaluate defense system of athletes exposed to an oxidant stress during intensive periods of training. It is usually measured in venous blood, however Youssef et al., comparing TAC of salivary and venous samplings in triathletes during training season found that even though saliva TAC did not reflect plasma TAC it could be used in the follow-up of athletes due to a strong correlation between the variation of saliva and plasma TAC during the training season [22]. MendozaNúñez et al., [23] after a 6-month Tai Chi training by elderly observed a significant increase of TAS concentration in saliva and the improvement of periodontal condition. Our data showed a significant increase in salivary TAS after training in basketball players.

Salivary peroxidase secreted by salivary glands is one of the salivary antioxidant agents being also an essential ingredient in the antibacterial salivary innate system [24]. It catalyzes the oxidation of thiocyanate ions $\left(\mathrm{SCN}^{-}\right)$by hydrogen peroxide $\left(\mathrm{H}_{2} \mathrm{O}_{2}\right)$, produced mainly by oral bacteria, and its end reaction end product - hypothiocyanite $\left(\mathrm{OSCN}^{-}\right)$is a strong oxidising agent that destroys oral bacteria. Therefore, the enzyme prevents the oral accumulation of potential cytotoxic levels of the hydrogen peroxide [25]. Salivary peroxidase can be subjected to alternation due to exercise. A noticeable increase in the SPO activity has been found in unstimulated saliva caused by a moderate intensity and an exhaustion exercise on a treadmill [26]. In contrast, our data did not show any increase in salivary SPO activity after basketball training, probably due to the workload being perceived by most players as "somehow hard".

Sialic acids, a family of monosaccharides, comprise more than 30 different variations of neuraminic acids. $\mathrm{N}$-acetylneuraminic acid (NANA) is present in saliva in the free state and occupies the terminal position of many glycoconjugates including glycoproteins and glycolipids. NANA plays also a role as a reactive oxygen scavenger [27]. Cavas et al., studied salivary free sialic acid in the elite judoists and observed its significant increase after training. They concluded that free sialic acid measurement could be an alternative oxidative stress marker in athletes [6]. However, our data did not show any significant changes in the free sialic acid level in basketball players after training.

Data on changes in salivary components after exercise are rather scarce. Chicharro et al., [7] studying levels of 16 elements in resting mixed saliva before and after strenuous physical exercise using cycle ergometer found significant increases in sodium and magnesium, and a decrease in manganese concentrations. Bretz and Carrilho [28] reported an increase in salivary calcium concentration after a swimming session in competitive swimmers. In contrast, our data showed no change in calcium level but an increase in magnesium output.

In team sports such as basketball, due to the situational nature of exercise, the subjective perceptual rating of intensity by the particular players can vary due to different high-intensity actions. Basketball requires frequent specific movements, accelerations, decelerations and changing of direction during running, rapid turnover and brief intense actions and upper-body demands of shooting, passing and rebounding. Lupo et al., [29] assessed the internal training load in 66 youth individuals during basketball sessions with the use of CR-10 scale modified by Foster's at [8] and found the mean RPE to be $6.7 \pm 1.3$ and ranging from 4 to 9 . The 
mean RPE for our players after a single training session was $4.7 \pm 1.64$ and ranged from 2 to 10 ; two thirds judged the training as, somehow hard" and "hard"; i.e. 4 and 5 respectively. Moreira et al., [30] examining the perceived exertion (RPE) in male basketball players using Foster's protocol observed significantly higher scores after an official match compared to the training session. In contrast to our data, they found correlation between pre-post cortisol changes and the rating of perceived exertion (RPE)-based internal load after the training session.

The basketball players were randomly selected, the sedentary group that was used as control consisted of individuals of the same age and sex as the subjects who were enrolled in the study. All the subjects involved in the study were in the pubertal stage of development and salivary samples were collected from the basketball players and the control group individuals at the same time. We did not consider developmental parameters such as height, weight, BMI in this study.

\section{CONCLUSION}

Within the limitation of the study we observed an increase in the levels of alpha-amylase and TAS in unstimulated saliva following a routine basketball training.

\section{ACKNOWLEDGMENTS}

This work was supported in part by Department of Conservative Dentistry and Paediatric Dentistry, Wroclaw Medical University.

\section{REFERENCES}

1. Chicharro JL, Lucía A, Pérez M, Vaquero AF, Ureña R. Saliva composition and exercise. Sports medicine. 1998 Jul 1;26(1):17-27.

2. Hayes LD, Bickerstaff GF, Baker JS. Interactions of cortisol, testosterone, and resistance training: influence of circadian rhythms. Chronobiology international. 2010 May 1;27(4):675-705.

3. Hill EE, Zack E, Battaglini C, Viru M, Viru A, Hackney AC. Exercise and circulating cortisol levels: the intensity threshold effect. Journal of endocrinological investigation. 2008 Jul 1;31(7):587-591.

4. Nunes LA, Macedo DV. Saliva as a diagnostic fluid in sports medicine: potential and limitations. Jornal Brasileiro de Patologia e Medicina Laboratorial. 2013 Aug;49(4):247-255.

5. Jenkins RR. Free radical chemistry. Relationship to exercise. Sports Med. 1988;5(3):156-170.

6. Cavas L, Arpinar P, Yurdakoc K. Possible interactions between antioxidant enzymes and free sialic acids in saliva: a preliminary study on elite judoists. International journal of sports medicine. 2005 Dec;26(10):832-835.
7. Chicharro JL, Serrano V, Ureña R, Gutierrez AM, Carvajal A, Fernandez-Hernando P, Lucia A. Trace elements and electrolytes in human resting mixed saliva after exercise. British journal of sports medicine. 1999 Jun 1;33(3):204-207.

8. Foster C, Florhaug JA, Franklin J, Gottschall L, Hrovatin LA, Parker S, Doleshal P, Dodge C. A new approach to monitoring exercise training. The Journal of Strength \& Conditioning Research. 2001 Feb 1;15(1):109-15.

9. De Oliveira VN, Bessa A, Lamounier RP, De Santana MG, De Mello MT, Espindola FS. Changes in the salivary biomarkers induced by an effort test. International journal of sports medicine. 2010 Jun;31(06):377-381.

10. He CS, Tsai ML, Ko MH, Chang CK, Fang SH. Relationships among salivary immunoglobulin A, lactoferrin and cortisol in basketball players during a basketball season. European journal of applied physiology. 2010 Nov 1;110(5):989-95.

11. Wu KP, Ke JY, Chung CY, Chen CL, Hwang TL, Chou MY, Wong AM, Hu CF, Lee YC. Relationship between unstimulated salivary flow rate and saliva composition of healthy children in Taiwan. Chang Gung Med J. 2008 May;31(3):281 286.

12. Capranica L, Condello G, Tornello F, Iona T, Chiodo S, Valenzano A, De Rosas M, Messina G, Tessitore A, Cibelli G. Salivary alpha-amylase, salivary cortisol, and anxiety during a youth taekwondo championship: An observational study. Medicine. 2017 Jul;96(28):e7272

13. Bordini B, Rosenfield RL. Normal pubertal development: Part I: The endocrine basis of puberty. Pediatr Rev. 2011;32(6):223-229.

14. Kiess W, Meidert A, Dressendörfer RA, Schriever K, Kessler U, Köunig A, Schwarz HP, Strasburger CJ. Salivary cortisol levels throughout childhood and adolescence: relation with age, pubertal stage, and weight. Pediatric research. 1995 Apr;37(4):502-506.

15. Azarbayjani MA, Fatolahi H, Rasaee MJ, Peeri M, Babaei R. The effect of exercise mode and intensity of sub-maximal physical activities on salivary testosterone to cortisol ratio and $\alpha$ amylase in young active males. International journal of exercise science. 2011;4(4):283-293.

16. Doan BK, Newton RU, Kraemer WJ, Kwon YH, Scheet TP. Salivary cortisol, testosterone, and T/C ratio responses during a 36-hole golf competition. International journal of sports medicine. 2007 Jun;28(06):470-479.

17. Moreira A, Crewther B, Freitas CG, Arruda AF, Costa EC, Aoki MS. Session RPE and salivary immune-endocrine responses to simulated and official basketball matches in elite young male athletes. J Sports Med Phys Fitness. 2012 Dec 1;52(6):682-687.

18. Bruzda-Zwiech A, Konieczka M, Hilt A, Daszkowska M, Grzegorczyk J, Szczepańska J. 
Salivary cortisol, alpha-amylase and immunoglobulin a responses to a morning session of basketball or volleyball training in boys aged 14-18 years. J Biol Regul Homeost Agents. 2017: 31(1):105-110.

19. Koibuchi E, Suzuki Y: Exercise upregulates salivary amylase in human (Review). Exp Ther Med. 2014; 7(4):773-777.

20. Ligtenberg AJ, Brand HS, van den Keijbus PA, Veerman EC. The effect of physical exercise on salivary secretion of MUC5B, amylase and lysozyme. Archives of oral biology. 2015 Nov 1;60(11):1639-1644.

21. Sachdev S., Davies K.J. Production, detection, and adaptive responses to free radicals in exercise. Free Radic Biol Med. 2008; 44(2):215-223

22. Youssef H, Groussard C, Machefer $G$ et al. Comparison of total antioxidant capacity of salivary, capillary and venous samplings: interest of the salivary total antioxidant capacity on triathletes during training season. J Sports Med Phys Fitness. 2008; 48 (4): 522-529

23. Mendoza-Núñez VM, Hernández-Monjaraz B, Santiago-Osorio E, Betancourt-Rule JM, RuizRamos M. Tai Chi exercise increases SOD activity and total antioxidant status in saliva and is linked to an improvement of periodontal disease in the elderly. Oxidative medicine and cellular longevity. $2014 ; 2014$
24. Mandel ID. The role of saliva in maintaining oral homeostasis. J Am Dent Assoc. 1989; 119(2): 298 304.

25. O'Brien PJ. Peroxidases. Chemico-biological interactions. 2000 Dec 1;129(1-2):113-139.

26. Damirchi A, Kiani M, Jafarian V, Sariri R. Response of salivary peroxidase to exercise intensity. European journal of applied physiology. 2010 Apr 1;108(6):1233-1237.

27. Iijima R, Takahashi H, Namme R, Ikegami S, Yamazaki M. Novel biological function of sialic acid ( $\mathrm{N}$-acetylneuraminic acid) as a hydrogen peroxide scavenger. FEBS letters. 2004 Mar 12;561(1-3):163-166.

28. Bretz WA, Carrilho MR. Salivary parameters of competitive swimmers at gas-chlorinated swimming-pools. Letter to Editors. J Sports Sci Med. 2013; 12 (1): 207-208.

29. Lupo C, Tessitore A, Gasperi L, Gomez MA. Session-RPE for quantifying the load of different youth basketball training sessions. Biology of sport. 2017 Mar;34(1):11-17.

30. Moreira A, McGuigan MR, Arruda AF, Freitas CG, Aoki MS. Monitoring internal load parameters during simulated and official basketball matches. The Journal of Strength \& Conditioning Research. 2012 Mar 1;26(3):861-6. 